\title{
COMUNIDADES QUILOMBOLAS SOB A PERSPECTIVA DA TRANSIÇÃO DEMOGRÁFICA
}

\section{QUILOMBOLAS COMMUNITIES FROM THE PERSPECTIVE OF DEMOGRAPHIC TRANSITION}

\author{
André Augusto Brandão* \\ Nilton Cesar dos Santos** \\ Amanda Lacerda Jorge ${ }^{\star * *}$
}

\section{Resumo}

Este artigo objetiva discutir a configuração demográfica atual das comunidades quilombolas brasileiras em relação ao perfil da transição demográfica verificado para o conjunto da população nacional nas últimas décadas. Os dados que utilizamos para a composição deste estudo derivam dos censos demográficos nacionais e de uma pesquisa realizada em 2011 que coletou informações populacionais e socioeconômicas no conjunto das 9.191 famílias que habitavam as 169 comunidades quilombolas que até 2010 haviam obtido o título definitivo de propriedade de seus territórios. Com a análise comparada dos dados, foi possível identificar em que variáveis a população quilombola se afasta ou se aproxima do perfil demográfico nacional. Na conclusão mostramos que, se por um lado esta população específica ainda não completou o seu processo de transição demográfica, começa a apresentar fortes tendências nesta direção.

Palavras-chave: Quilombolas. Populações tradicionais. Transição demográfica. Perfil demográfico.

\begin{abstract}
This paper discusses the current demographic configuration of the quilombolas communities in relation to the profile of the demographic transition seen for the whole brazilian population in recent decades. The data used for the composition of this study are from Brazilian Institute of Geography and Statistics and from a survey of 9.191 families of 169 residents quilombolas communities from 55 counties from 14 Brazilian states. With the comparative analysis of the data, it was possible to identify which variables the quilombola population moves away or approaches the national demographic profile. In conclusion we show that, if in one hand this specific population has not yet completed its demographic transition process, begins to exhibit strong tendencies in this direction.
\end{abstract}

Key words: Quilombolas. Traditional populations. Demographic transition. Demographic profile.

\section{Introdução}

Este artigo objetiva discutir a configuração demográfica das comunidades quilombolas brasileiras em relação ao perfil atual da população em geral, considerando que este último é

\footnotetext{
* Professor da Universidade Federal Fluminense (UFF)/ Brasil, doutor em Ciências Sociais pela UERJ/Brasil. E-mail: andre_brandao@id.uff.br.

** Doutor em Política Social pela UFF/Brasil e estatístico da Eletrobrás. E-mail: nilton.santos@eletrobras.com.

${ }^{* * *}$ Doutora em Política Social pela UFF/Brasil e pesquisadora da DATAUFF. E-mail: amandalacerda@id.uff.br.
} 
- pelo menos em tese - o resultado de um processo de transição demográfica em andamento no conjunto do país. Para tanto, faremos inicialmente uma breve caracterização do grupo social quilombola, que desde 1988 se tornou alvo da agenda do Estado brasileiro. Em seguida, apontaremos os elementos teóricos gerais que informam o debate sobre a transição demográfica, bem como nos apoiaremos na literatura especializada para mostrar o caminho que o país trilhou neste terreno. Somente após esta demarcação apresentaremos os dados demográficos nacionais e aqueles relativos especificamente à população quilombola.

Os dados secundários nacionais foram recolhidos principalmente nos censos demográficos. Já os dados referentes à população quilombola, derivam de pesquisa de base censitária, realizada em 2011, junto às 169 comunidades quilombolas que haviam, até 2010, recebido o título definitivo de propriedade coletiva de seu território. Nesta pesquisa, desenvolvida pelo Núcleo de Avaliação de Políticas Sociais da Universidade Federal Fluminense (DATAUFF), o objetivo era mapear o perfil socioeconômico das comunidades, sua configuração no campo da segurança alimentar e as características do acesso destas aos programas sociais (DATAUFF, 2012). Os dados coletados possibilitaram a produção de um banco de dados com informações demográficas robustas. Efetivamente, foram aplicados questionários socioeconômicos em 9.191 famílias quilombolas existentes nestas 169 comunidades, que estavam espalhadas por 55 municípios de 14 estados da federação.

Vale ressaltar que, para o conjunto da população, é possível estabelecer séries de dados. Já para as comunidades quilombolas, este procedimento não é possível, pois temos somente os resultados obtidos com a pesquisa de 2011, que representam a configuração demográfica do grupo naquele ano.

\section{O debate acerca da caracterização das comunidades quilombolas?}

Segundo informações da Secretaria Especial de Políticas de Promoção da Igualdade Racial (SEPPIR), a Fundação Cultural Palmares (FCP) havia emitido até 2012, a certificação como "Quilombola" para 2.040 comunidades, 63,0\% destas situadas no Nordeste do país (SEPPIR, 2012).

É importante frisar que as comunidades quilombolas têm ingresso na agenda das políticas públicas brasileiras a partir de 1988, mais especificamente quando estas são citadas na constituição federal e ganham com isto alguma visibilidade. Tais referências constitucionais aos quilombolas aparecem em dois momentos. No próprio corpo da Constituição, o parágrafo $5^{\circ}$ do artigo 216 (" $\$ 5^{\circ}$ Ficam tombados todos os documentos e os sítios detentores de reminiscências históricas dos antigos quilombos") possui preocupação vinculada à preservação do patrimônio cultural nacional e dos bens materiais e imateriais que dizem respeito à identidade e memória dos grupos que formaram a sociedade brasileira. Já especificamente no Ato das Disposições 
Constitucionais Transitórias" (ADCT), o artigo 68 define: "Aos remanescentes de quilombos que estejam ocupando suas terras é reconhecida a propriedade definitiva, devendo o Estado emitirlhes os títulos definitivos".

Após estas referências, ocorre de forma lenta e progressiva um movimento de incorporação deste segmento populacional à agenda do Estado nacional brasileiro. Em 1995 a primeira comunidade quilombola recebe a titulação de seu território ${ }^{2}$. Mas somente em 2004 é criado um programa de corte social de base federal, diretamente voltado para este grupo.

Será o artigo 68 do ADCT que atrairá mais atenção no campo político, uma vez que se referia à propriedade da terra, elemento de redistribuição econômica altamente disputado e escasso em nossa sociedade. Na medida em que estas comunidades quilombolas se caracterizam pela organização em torno de uma identidade étnica diferenciada e da dependência de seus territórios para a viabilização de sua reprodução física, social, econômica e cultural, a potencial garantia da propriedade definitiva destes levará à construção, ainda nos anos 1990, de um movimento social quilombola com articulação nacional.

Não foi até o momento construído um mapeamento mais detalhado dos debates que antecederam a redação do Artigo 68 dos Atos das Disposições Transitórias da Carta Constitucional de 1988. De qualquer forma, importa frisar que naquele dispositivo constitucional se nomeava e se atribuíam direitos a um heterogêneo conjunto de comunidades de predominância negra que, salvo raras exceções, ainda não se pensavam como "remanescentes das comunidades de quilombos".

É possível supor que a definição e a "imagem" do que seria o quilombo, subjacente ao texto constitucional e ao próprio senso comum nacional no momento, ligava tais comunidades a ocorrências de fugas de escravos e formação a partir daí de comunidades isoladas que resistiam a ações de recaptura. Para a grande maioria dos brasileiros, naquele ano de 1988 a representação do termo "quilombo" estava ainda ancorada em Zumbi dos Palmares - tratavase, portanto, muito mais de uma representação do que de uma leitura empírica da realidade destas populações.

Desta forma, no processo de operacionalização do Artigo 68, a dificuldade de produção do direito de propriedade da terra para os "remanescentes das comunidades de quilombos" ficou transparente por conta de dois aspectos: a) as comunidades negras rurais (e depois também urbanas), que poderiam ser caracterizadas como "quilombolas" não se mostravam homogêneas entre si; e b) estas não constituíam algo como resquícios arqueológicos que poderiam ser submetidos a um conjunto maior ou menor de testes e medições que teriam a propriedade de diagnosticar uma "verdade" específica acerca de suas origens.

$1 \mathrm{O}$ Ato das disposições Constitucionais Transitórias, conhecido como ADCT, agrupa matérias que, na perspectiva dos legisladores, não foram suficientemente discutidas e assim aguardam ainda novos aprofundamentos, modificações ou complementações legais. Deriva disto o uso do termo "transitório".

2Trata-se da comunidade de Boa Visto no município de Oriximiná, estado do Pará. 
Do difícil diálogo entre os agentes estatais e da forte e progressiva pressão do movimento negro e do movimento quilombola que se expandia, resultou em crescente alteração na forma de interpretação do termo "remanescentes das comunidades de quilombos". Cientistas sociais situados nas universidades brasileiras, construindo um discurso especializado, trabalharam no sentido de estabelecer uma interpretação capaz de alargar a compreensão do artigo 68 do ADCT. Lançando mão do texto seminal "Os grupos étnicos e suas fronteiras", de Fredrik Barth (2000), a Associação Brasileira de Antropologia divulgou em outubro de 1994 o "Documento do Grupo de Trabalho sobre Comunidades Negras Rurais", no qual define um significado para a nomeação contida no texto constitucional: “'Remanescente de quilombo', é utilizado pelos grupos para designar um legado, uma herança cultural e material que lhes confere uma referência presencial no sentimento de ser e pertencer a um lugar e a um grupo específico" (ABA, 1994).

Desenhar as comunidades "quilombolas" por essa perspectiva, produziu elementos que colaboraram para visibilizar novos formatos possíveis para a classificação destes grupos frente ao Estado brasileiro. Ao receber este discurso, parte das comunidades anteriormente caracterizadas como negras rurais, passaram a acionar a identidade "quilombola", que até há pouco tempo elas próprias desconheciam.

Desde então, o campo das ciências sociais, com destaque para os antropólogos, se refere aos quilombolas a partir da noção de "etnicidade" (BARTH, 2000). Nesta versão, grupos étnicos emergiriam dos processos de diferenciação construídos a partir das interações. No contexto destas, são elaboradas classificações e autoclassificações que definem fronteiras sociais e simbólicas. A categoria "quilombola" é desencaixada de uma chave histórica (como resquícios do período escravista), ou biologicamente definida (através de elementos fenotípicos), para ser reconhecida a partir de um processo de mobilização étnica. Assim, os quilombolas deveriam ser tomados como entidades sociais que emergem da diferença subjetivamente produzida nas relações com grupos externos.

Mais especificamente, segundo Barth (2000) as "fronteiras étnicas" se formam no contato com o outro, que é de fundamental importância para a autodefinição dos grupos a partir de diferenças que surgem quando se estabelece tal relação. A interação seria a responsável por trazer informação e incorporação de elementos que vão se integrar a vida do grupo. É importante notar que para Barth (2000), os elementos que caracterizam o grupo étnico serão definidos pelo próprio, ou seja, são aqueles que os componentes identificam como significativos. Nesta perspectiva teórica, os grupos étnicos levam em consideração - pela impossibilidade mesmo de ignorar - a forma como os que lhes são externos o “categorizam”. Assim, a sua própria autodefinição somente ganha sentido na medida em que se relaciona com as definições externas. A nova "leitura" das comunidades que se auto referenciavam como quilombolas apontava que independente da forma como estas foram construídas, o importante seria a existência de uma continuada reprodução material e cultural do grupo. 
Tal formato de interpretação somente se tornará dominante nas práticas do Estado a partir de 2003. É a partir deste momento, portanto, que a legislação começa a interpretar de forma diferenciada o que seriam os quilombolas. Nesta direção, o decreto número 4.887, de 20 de novembro de 2003 , em seu artigo $2^{\circ}$ considera:

Remanescentes das comunidades dos quilombos os grupos étnico-raciais, segundo critérios de auto atribuição, com trajetória histórica própria, dotados de relações territoriais específicas, com presunção de ancestralidade negra relacionada com a resistência à opressão histórica sofrida.

Parágrafo $1^{\circ}$. Para os fins deste Decreto, a caracterização dos remanescentes das comunidades dos quilombos será atestada mediante auto definição da própria comunidade.

Parágrafo $2^{\circ}$. São terras ocupadas por remanescentes das comunidades dos quilombos as utilizadas para a garantia de sua reprodução física, social e cultural. ${ }^{3}$

No que tange às políticas sociais voltadas para esta população específica, em 2004 o Governo Federal lançou, através da Secretaria de Políticas para Promoção da Igualdade Racial, o Programa Brasil Quilombola. No desenho deste Programa, fica claro que outros órgãos componentes do Estado também investiram em justificações que interpretam de forma diferencial o conceito de remanescente de quilombo.

Assim, o Programa Brasil Quilombola os caracteriza como um "grupo étnico" que teria sua singularidade demarcada por uma "ancestralidade comum", por "formas de organização política e social" e ainda por "elementos linguísticos e religiosos" (SEPPIR, 2004, p. 10). Nesta perspectiva, a especificidade dos quilombolas seria dada por um conjunto de práticas sociais e econômicas que envolveriam o uso comum da terra. Tais práticas atestariam a proximidade entre os quilombos do passado e os quilombos atualmente encontrados no país.

Mas quais as características socioeconômicas destas comunidades quilombolas? Pesquisas realizadas a partir de 2006 e sintetizadas em Brandão, Dalt e Gouveia (2010), apontam que tais comunidades atualmente possuem, apesar de uma ampla diversidade, alguns elementos comuns. Um destes é a prevalência da localização em área rurais, embora encontremos também algumas poucas em espaços urbanos no Brasil. Por conta disto a imensa maioria dos responsáveis pelos domicílios trabalha em atividades agrícolas, principalmente na qualidade de agricultores de subsistência - embora sejam encontrados também trabalhadores rurais autônomos e assalariados rurais. Estas atividades de subsistência são desenvolvidas em geral com base no núcleo familiar, o que produz situações recorrentes de vinculação ao trabalho agrícola por parte de crianças e adolescentes nas comunidades.

3 O Decreto 4.887/2003 é alvo de uma ação direta de inconstitucionalidade, movida em 2004 pelo então Partido da Frente Liberal (atualmente, Democratas). O processo foi incluído em 2018 no STF, sendo validade a constitucionalidade do referido Decreto. 
De fato, as comunidades quilombolas compõem o pequeno campesinato, que sobrevive da produção descapitalizada e em pequena escala de insumos agrícolas que são consumidos pelo núcleo familiar e comercializados de forma esporádica quando há excedente e quando existe mercado de consumo. Neste sentido, a renda das famílias tende a ser muito baixa e a insegurança alimentar é elevada.

No geral os quilombolas apresentam índices baixos de escolaridade. Especificamente entre os responsáveis pelos domicílios há uma elevada parcela de indivíduos que chegam somente a quatro anos completos de estudos. Por fim, a infraestrutura das comunidades quilombolas está muito aquém do ideal, sendo quase inexistente a presença de redes de coleta e esgoto e de fornecimento de água.

\section{O que é a chamada "transição demográfica"?}

A chamada teoria da transição demográfica está baseada na relação entre crescimento populacional e desenvolvimento socioeconômico e já vem sendo discutida desde as primeiras décadas do século XX (THOMPSON, 1929; LANDRY, 1934; ALVES, 2002). Tal perspectiva foi diretamente influenciada pelas mudanças na dinâmica do crescimento da população europeia, advindas das alterações observadas nas taxas de natalidade e de mortalidade. Este conjunto de alterações teria produzido elementos importantes para a continuidade e o aprofundamento do desenvolvimento econômico e do processo de modernização destas sociedades.

Mas porque transição? A teoria aponta para a passagem de uma sociedade pré-industrial (de base social rural) caracterizada por taxas de natalidade e mortalidade elevadas, para uma sociedade industrial (com base social urbana), caracterizada por taxas de natalidade e de mortalidade mais reduzidas. Essa transição entre perfis de ordenamento social e por decorrência de arranjos demográficos, promoveria momentos de desajustes entre as taxas de natalidade e de mortalidade, gerando períodos de instabilidade demográfica. Além disto, tal movimento de redução de ambas as taxas produziria uma aceleração no crescimento da população, que voltaria a ter seu ritmo equilibrado, em um momento posterior, quando então as taxas de natalidade fossem reduzidas (ALVES, 2002; SOARES, 2000).

A literatura identifica diferentes fases no processo de transição demográfica. Teríamos de início o período pré-transição, que é definido pelo baixo crescimento vegetativo da população e por uma estrutura etária jovem. Estariam nesta fase as sociedades que apresentam altas taxas de natalidade e mortalidade em paralelo.

Já no cerne da transição, a primeira fase seria marcada pelo incremento do ritmo de crescimento demográfico, pois há queda na mortalidade, mas não se alteram as taxas de natalidade. A segunda fase configura diminuição do crescimento populacional, resultado da diminuição da natalidade (ainda que a mortalidade continue em queda). Com isso há tendência ao envelhecimento da população. Ainda que se mantenha - como resultado da fase anterior - 
um período de alta presença de população em idade ativa, este contingente tende a diminuir em seguida (ALVES, 2002).

Construída a partir da experiência dos países desenvolvidos, restava ainda debater o quanto tal perspectiva teórica poderia ser generalizável para países pobres e não-desenvolvidos do ponto de vista socioeconômico. É claro que dinâmicas locais - tanto de fundo econômico, quanto vinculadas a opções de políticas públicas - podem ter maiores ou menores impactos sobre os processos demográficos. Para além de situações imponderáveis como guerras, catástrofes climáticas, fluxos migratórios etc.

O caso brasileiro parece apontar para um caminho de transição próximo aos moldes indicados pela teoria, apesar de algumas diferenças regionais visíveis. Passamos agora a trabalhar com estes dados nacionais e, em paralelo, mostrar como a configuração demográfica das comunidades quilombolas em 2011 se relaciona com o contexto mais amplo.

\section{A transição demográfica no Brasil e as comunidades quilombolas}

Comecemos com a taxa de fecundidade total, que expressa o número médio de nascidos vivos por mulher ao final de seu período reprodutivo. Não temos este dado para as comunidades quilombolas. No entanto, foi possível calcular o número médio de filhos por família nesta população específica.

Quadro 1 - Taxa de fecundidade total - Brasil 1950-2010 e número médio de filhos por famílias nas comunidades quilombolas tituladas - 2011

\begin{tabular}{lccccccccc}
\cline { 2 - 7 } & $\mathbf{1 9 5 0}$ & $\mathbf{1 9 6 0}$ & $\mathbf{1 9 7 0}$ & $\mathbf{1 9 8 0}$ & $\mathbf{1 9 9 1}$ & $\mathbf{2 0 0 0}$ & $\mathbf{2 0 1 0}$ & $\begin{array}{c}\text { Comunidades } \\
\text { quilombolas } \\
\mathbf{2 0 1 1 ^ { * }}\end{array}$ \\
\cline { 2 - 8 } $\begin{array}{l}\text { Taxa de fecundidade } \\
\text { total no Brasil }\end{array}$ & 6,2 & 6,3 & 5,8 & 4,4 & 2,9 & 2,4 & 1,9 & 2,1 \\
\hline
\end{tabular}

Fonte: Cálculos a partir de IBGE - Censos demográficos nacionais de 1950 a 2010 e Banco de dados do DATAUFF.

* Número médio de filhos por família nas comunidades quilombolas tituladas (2011).

O que vemos no caso nacional é uma brusca diminuição da natalidade no período entre 1970 e 2010. É significativo verificar que as 9.191 famílias quilombolas investigadas em 2011 apresentavam número de filhos por família baixo. Apesar das diferenças entre a definição da taxa de fecundidade total e o simples cálculo do número de filhos por família, devemos ressaltar que a população quilombola alvo desta investigação é predominantemente rural (das 169 comunidades pesquisadas, 
somente 2 são urbanas), o que nos faria - em tese - esperar um número mais elevado nesta variável. Neste sentido, o número médio de filhos encontrados nas famílias pode estar representando ou uma diminuição da natalidade (que não podemos precisar em que momento começou a ocorrer), ou uma elevada mortalidade infantil (o que nos parece menos provável, na medida em que este indicador tem apresentado progressiva melhora no país ao longo das últimas décadas).

$\mathrm{Na}$ Tabela 1 são apresentados dados referentes à idade da população que marcam a trajetória demográfica ao longo da segundo metade do século XX. Para as comunidades quilombolas são apresentados dados coletados em 2011.

Tabela 1 - Indicadores de estrutura etária - Brasil 1950-2010 e comunidades quilombolas tituladas - 2011

\begin{tabular}{|c|c|c|c|c|c|c|c|c|}
\hline Variáveis & 1950 & 1960 & 1970 & 1980 & 1991 & 2000 & 2010 & $\begin{array}{r}\text { Comunidades } \\
\text { quilombolas } \\
2011\end{array}$ \\
\hline Idade mediana & 18 anos & 18 anos & 19 anos & 20 anos & 22 anos & 25 anos & 27 anos & 20 anos \\
\hline $\begin{array}{l}\text { Menor de } 15 \text { anos } \\
(\%)\end{array}$ & 41,8 & 42,6 & 41,7 & 38,2 & 34,8 & 29,6 & 24,1 & 38,6 \\
\hline De 15 a 59 anos (\%) & 53,9 & 52,6 & 53,1 & 55,7 & 58,0 & 61,8 & 65,1 & 53,7 \\
\hline \multicolumn{9}{|l|}{60 anos e mais } \\
\hline (\%) & 4,3 & 4,8 & 5,2 & 6,1 & 7,3 & 8,6 & 10,8 & 7,7 \\
\hline
\end{tabular}

Fonte: Cálculos a partir de IBGE - Censos demográficos nacionais de 1950 a 2010 e Banco de dados do DATAUFF.

Como vemos, em nível mais geral e considerando o conjunto da população, o Brasil parece ter vivido desde 1950 um processo semelhante ao que podemos caracterizar como uma transição demográfica. A idade mediana apresentou elevação significativa de 9 anos, a população de crianças e jovens diminuiu relativamente e, com o aumento da expectativa de vida ao nascer (que evoluiu de 45,5 anos em 1950 para 73,5 anos em 2010 - Vasconcelos e Gomes, 2012) ocorreu progressivo incremento do quantitativo de pessoas com 60 anos e mais. Ainda sob o impacto da alta natalidade anterior (que identificamos no Quadro 1), verificamos também o incremento da população em idade ativa.

Nestas variáveis, as 9.191 famílias encontradas nas comunidades quilombolas tituladas que foram pesquisadas em 2011 apresentam uma configuração um pouco diferenciada, que remete ao Brasil dos anos 1970 e 1980. Vejamos. De início a idade mediana de 20 anos corresponde àquela alcançada no país em 1980. Como o número médio de filhos por família em 2011 era baixo (como mostra o Quadro 1), é possível levantar a hipótese de que há ainda sobre a idade mediana o peso da natalidade elevada anterior. $O$ mesmo se verifica no percentual de pessoas em idade ativa (de 15 a 59 anos). Nas comunidades, o índice encontrado em 2011 é semelhante ao existente no Brasil na década de 1970. Já o percentual de idosos, embora quase 3 
pontos percentuais menor que o encontrado no conjunto do país em 2010, é um pouco superior àquele verificado em 1990.

A Tabela 2 apresenta indicadores que reputamos ter peso fundamental para o debate que estamos traçando aqui. O primeiro constitui o Índice de Envelhecimento, que representa a proporção de pessoas de 60 e mais anos de idade para cada 100 pessoas menores de 15 anos. O segundo é a Razão de Dependência Total, que expressa a proporção de menores de 15 anos e de pessoas de 60 anos e mais em relação à população entre 15 e 59 anos. Assim, este indicador possibilita identificar o peso das faixas etárias que - pelo menos em teoria - não deveriam ser economicamente ativas, sobre aquela caracterizada como em idade ativa. É possível desdobrar a Razão de Dependência Total em dois outros indicadores. O primeiro especificamente relacionado ao peso da população jovem sobre a população em idade ativa (o que equivale a Razão de Dependência Jovem) e o segundo ligado ao peso dos maiores de 60 anos sobre os que possuem entre 15 e 59 anos (trata-se da Razão de Dependência Idoso).

Tabela 2 - Indicadores demográficos - Brasil 1950-2010 e comunidades quilombolas tituladas - 2011

\begin{tabular}{lrrrrrrrr}
\hline Indicadores & 1950 & 1960 & 1970 & 1980 & 1991 & 2000 & 2010 & $\begin{array}{r}\text { Comunidades } \\
\text { quilombolas }\end{array}$ \\
& & & & & & & & \\
& & & & & & & 2011 \\
\hline Índice de envelhecimento (\%) & 10,3 & 11,2 & 12,4 & 15,9 & 20,9 & 28,9 & 44,8 & 20,1 \\
Razão de dependência total (\%) & 85,5 & 90,0 & 88,3 & 79,5 & 72,5 & 61,7 & 53,6 & 86,4 \\
Razão de dependência jovem (\%) & 77,6 & 81,0 & 78,6 & 68,6 & 60,0 & 47,9 & 37,0 & 71,9 \\
Razão de dependência idoso (\%) & 8,0 & 9,0 & 9,7 & 10,9 & 12,5 & 13,8 & 16,6 & 14,4 \\
\hline
\end{tabular}

Fonte: Cálculos a partir de IBGE - Censos demográficos nacionais de 1950 a 2010 e Banco de dados do DATAUFF.

É preciso analisar os dados contidos na tabela 2 acima com cuidado. Isto porque, entre as comunidades tradicionais em geral (o que inclui os quilombolas), as representações acerca do trabalho e mesmo da chamada idade ativa não são redutíveis àquelas que circulam no contexto mais geral da sociedade brasileira. Assim, os dados extraídos da ampla pesquisa realizada junto às comunidades quilombolas tituladas devem ser tomados como um proxy que possibilita comparações hipotéticas, e não como indicadores absolutos. Dito isso, os elementos dispostos na Tabela 2 continuam, sem exceção, a corroborar a perspectiva de que o Brasil atravessa, de fato, um período de transição demográfica. O Índice de Envelhecimento da população quadriplicou no período, o que duplicou a Razão de Dependência Idoso. Já a Razão de Dependência Jovem foi reduzida em 40 pontos percentuais. Na medida em que o contingente populacional jovem é muito maior que o dos idosos, a Razão de Dependência Total decresceu cerca de 30 pontos percentuais no país entre 1950 e 
1980.

Para os quilombolas os índices acima acompanham os números expressos na Tabela 1. De início, o índice de envelhecimento da população quilombola pesquisada se aproxima do encontrado para o Brasil nos anos 1990, mas está longe de margear o resultado nacional para 2010. Isto nos leva à hipótese de que a esperança de vida ao nascer entre os quilombolas é menor do que a existente no conjunto do país, o que explica também a Razão de Dependência Idoso menor neste grupo específico. No entanto, também é possível levantar a hipótese de que a regulamentação da previdência especial rural (nos anos 1990) e a progressiva adesão dos quilombolas a este regime de seguridade (JORGE, 2012), possibilitam aos mais idosos ganhos de renda que redundarão em redução relativa das dificuldades materiais, o que poderá ter impactos futuros no índice de envelhecimento.

Como resultado de uma população menor de 15 anos ainda elevada, quando comparada ao conjunto do país, a Razão de Dependência Jovem entre os quilombolas é quase o dobro da nacional, se aproximando do perfil vigente no Brasil entre as décadas de 1970 e 1980. Esta configuração pode ser caudatária de processos de migração rural-urbano desenvolvidos por adultos em idade ativa, uma vez que tais populações ocupam em geral territórios com baixo dinamismo econômico (BRANDÃO, DALT e JORGE, 2015). No entanto, este tipo de dado não foi mapeado na pesquisa de 2011 que oferece a base fundamental para este artigo.

$\mathrm{O}$ que os resultados expostos nas Tabelas 1 e 2 indicam é que os quilombolas estão muito longe do final do ciclo de transição demográfica que verificamos no conjunto do país. Por consequência, elementos demográficos que sobredeterminam contextos de vulnerabilidade social se mostram evidentes. A elevada Razão de Dependência Jovem, por exemplo (que caracteriza a situação em que o montante de renda levantada pela família deve ser dividido por maior número de pessoas) está - ao lado de inúmeros fatores - na matriz da pobreza disseminada entre esta população (BRANDÃO, DALT e JORGE, 2015).

Vejamos agora como se apresentam estes mesmos valores desagregados pelas regiões do Brasil.

Tabela 3 - Taxa de fecundidade total - Brasil e Regiões 1970-2010 e número médio de filhos por famílias nas comunidades quilombolas tituladas por Região - 2011

\begin{tabular}{lrrrrrrr}
\hline Taxa de fecundidade total & 1970 & 1980 & 1991 & 2000 & 2010 & $\begin{array}{r}\text { Comunidades quilombolas } \\
\end{array}$ \\
\hline Brasil & 5,80 & 4,40 & 2,90 & 2,40 & 1,90 & 2,10 \\
Região Norte & 8,15 & 6,40 & 3,99 & 3,16 & 2,47 & 2,30 \\
Região Nordeste & 7,53 & 6,20 & 3,38 & 2,69 & 2,06 & 2,00 \\
Região Sudeste & 4,60 & 3,50 & 2,28 & 2,10 & 1,70 & 1,70 \\
Região Sul & 5,42 & 3,60 & 2,45 & 2,24 & 1,78 & 2,00 \\
Região Centro-Oeste & 6,42 & 4,50 & 2,60 & 2,25 & 1,92 & 1,60 \\
\hline
\end{tabular}

Fonte: Cálculos a partir de IBGE - Censos demográficos nacionais de 1970 a 2010 e Banco de dados do DATAUFF. 
* Número médio de filhos por família nas comunidades quilombolas tituladas (2011).

A Tabela 3 mostra que a intensa diversidade na fecundidade entre as regiões arrefeceu ao longo destes 40 anos, na medida em que um gradiente que ia de 4,60 a 8,15 filhos em 1970 se viu reduzido a um intervalo entre 1,70 e 2,47 filhos em 2010. Ainda assim, as regiões Norte e Nordeste são as que apresentam as maiores taxas de fecundidade quando comparadas com o conjunto da população. O Sudeste, intensamente mais urbanizado, segue na frente desta tendência de diminuição da natalidade que seria típica da transição demográfica. No entanto, devemos ressaltar que em 2010 todas as regiões, com exceção da Norte, tiveram suas taxas de fecundidade abaixo do que é considerado o nível de reposição, ou seja 2,1 filhos por mulher.

Entre as 9.191 famílias das comunidades quilombolas pesquisadas, os resultados referentes ao número de filhos nas famílias não seguem de forma linear o comportamento das regiões brasileiras para a taxa de fecundidade. Se, por um lado, a maior média de filhos por família está na região Norte, as regiões Nordeste e Sul apresentam média idêntica. Já as menores médias são encontradas entre as comunidades quilombolas do Centro-Oeste e do Sudeste, respectivamente.

Quadro 2 - Indicadores de estrutura etária - Regiões do Brasil 1970-2010 e comunidades quilombolas tituladas - 2011

\begin{tabular}{llcccccc}
\hline Região & Indicadores & $\mathbf{1 9 7 0}$ & $\mathbf{1 9 8 0}$ & $\mathbf{1 9 9 1}$ & $\mathbf{2 0 0 0}$ & $\mathbf{2 0 1 0}$ & $\begin{array}{c}\text { Comunidades } \\
\text { quilombolas }\end{array}$ \\
& & & & & & & $\mathbf{2 0 1 1}$ \\
\hline \multirow{5}{*}{ NORTE } & Idade mediana & 16 & 16 & 18 & 20 & 22 & 19 \\
& Menos que 15 & $47,0 \%$ & $46,0 \%$ & $43,0 \%$ & $37,0 \%$ & $31,0 \%$ & $39,0 \%$ \\
& De 15 a 59 & $49,0 \%$ & $50,0 \%$ & $53,0 \%$ & $57,0 \%$ & $61,0 \%$ & $54,0 \%$ \\
& 60 e mais & $4,0 \%$ & $4,0 \%$ & $5,0 \%$ & $5,0 \%$ & $8,0 \%$ & $7,0 \%$ \\
\hline \multirow{3}{*}{ NORDESTE } & Menor que 15 & $45,0 \%$ & $43,0 \%$ & $39,0 \%$ & $33,0 \%$ & $27,0 \%$ & $38,0 \%$ \\
& Idade mediana & 17 & 17 & 19 & 22 & 27 & 20 anos \\
& De 15 a 59 & $50,0 \%$ & $50,0 \%$ & $53,0 \%$ & $59,0 \%$ & $63,0 \%$ & $54,0 \%$ \\
& 60 e mais & $5,0 \%$ & $6,0 \%$ & $7,0 \%$ & $8,0 \%$ & $10,0 \%$ & $8,0 \%$ \\
\hline \multirow{2}{*}{ SUDESTE } & Idade mediana & 20 & 22 & 25 & 27 & 32 & 22 anos \\
& Menor que 15 & $38,0 \%$ & $34,0 \%$ & $31,0 \%$ & $27,0 \%$ & $22,0 \%$ & $36,0 \%$ \\
& De 15 a 59 & $56,0 \%$ & $59,0 \%$ & $61,0 \%$ & $64,0 \%$ & $66,0 \%$ & $55,0 \%$ \\
& 60 e mais & $6,0 \%$ & $6,0 \%$ & $8,0 \%$ & $9,0 \%$ & $12,0 \%$ & $9,0 \%$ \\
\hline
\end{tabular}




\begin{tabular}{llcccccc}
\hline \multirow{2}{*}{ SUL } & Idade mediana & $\begin{array}{c}18 \\
\text { anos }\end{array}$ & $\begin{array}{c}20 \\
\text { anos }\end{array}$ & $\begin{array}{c}24 \\
\text { anos }\end{array}$ & $\begin{array}{c}27 \\
\text { anos }\end{array}$ & $\begin{array}{c}32 \\
\text { anos }\end{array}$ & 19 anos \\
& Menor que 15 & $43,0 \%$ & $36,0 \%$ & $32,0 \%$ & $27,0 \%$ & $22,0 \%$ & $38,0 \%$ \\
& De 15 a 59 & $53,0 \%$ & $58,0 \%$ & $60,0 \%$ & $63,0 \%$ & $66,0 \%$ & $56,0 \%$ \\
& 60 e mais & $5,0 \%$ & $6,0 \%$ & $8,0 \%$ & $9,0 \%$ & $12,0 \%$ & $6,0 \%$ \\
\hline \multirow{2}{*}{ CENTRO- } & Idade mediana & 17 & 18 & 21 & 24 & 27 & 21 anos \\
-OESTE & Menor que 15 & $45,0 \%$ & $41,0 \%$ & $35,0 \%$ & $30,0 \%$ & $24,0 \%$ & $38,0 \%$ \\
& De 15 a 59 & $52,0 \%$ & $55,0 \%$ & $60,0 \%$ & $63,0 \%$ & $67,0 \%$ & $51,0 \%$ \\
& 60 e mais & $3,0 \%$ & $4,0 \%$ & $5,0 \%$ & $7,0 \%$ & $9,0 \%$ & $11,0 \%$ \\
\hline
\end{tabular}

Fonte: Cálculos a partir de IBGE - Censos demográficos nacionais de 1970 a 2010 e Banco de dados do DATAUFF.

Vemos no Quadro 2 acima como a região Norte parece estar em momento da transição demográfica diferente das demais. Um fator que corrobora esta afirmação é a idade mediana de 22 anos nesta região em 2010, que fica 10 anos abaixo da encontrada nas regiões Sul e Sudeste. Estas últimas, por sua vez, ainda apresentam idade mediana 5 anos superior àquela existente no Centro-Oeste e no Nordeste. Ou seja, o processo de envelhecimento da população de fato anda a passos mais largos no eixo Sul-Sudeste.

Exatamente por isso, o percentual de pessoas com menos de 15 anos de idade e com 60 anos e mais obedece à variação semelhante a obtida para a idade mediana. $\mathrm{O}$ maior percentual de crianças e adolescentes em 2010 (quase 1/3 da população total) está no Norte do país. Os menores valores relativos estão, mais uma vez, nas regiões Sul e Sudeste. A mesma lógica relativa ao envelhecimento da população se repete no percentual de pessoas com 60 anos e mais, que é maior no Sul-Sudeste e menor no Norte.

A configuração encontrada entre as comunidades quilombolas, relativa a estas variáveis, não reflete de forma linear os contornos verificados em nível nacional. A idade mediana, por exemplo, é muito assemelhada entre as regiões, variando de 19 anos nas regiões Norte e Sul a 22 anos na região Sudeste. Já o percentual de população com 60 anos e mais tende a ser ligeiramente mais baixo entre os quilombolas com exceção somente do Centro-Oeste onde esta relação se inverte.

As diferenças entre os quilombolas e a população nacional voltam a ser elevadas quando verificamos os percentuais de população com menos de 15 anos. A variação vai de $36,0 \%$ no Sudeste a 39,0\% no Norte (ficando as demais regiões na casa dos 38,0\%). Ou seja, apesar de uma configuração atual de poucos filhos por família, podemos supor que a herança de altas taxas de natalidade anteriores gerou uma situação na qual o percentual de crianças e adolescentes é alto e com pouca variação entre as regiões. Assim, mesmo onde o conjunto da população já "envelheceu" mais (como no Sudeste e no Sul), os quilombolas continuam com amplo percentual de população com baixa idade. 
Também a presença de população em idade ativa é sempre menor nas comunidades quilombolas do que no conjunto. No entanto, para os dois grupos as variações regionais são discretas (de $61,0 \%$ a $67,0 \%$ entre as regiões do Brasil e de 51,0\% a 56,0\% entre os quilombolas nas cinco regiões).

As consequências destas configurações se expressam nos indicadores que compõem o Quadro 3 abaixo.

Quadro 3 - Indicadores demográficos - Regiões do Brasil 1970-2010 e comunidades quilombolas tituladas - 2011

\begin{tabular}{|c|c|c|c|c|c|c|c|}
\hline Região & Indicadores & 1970 & 1980 & 1991 & 2000 & 2010 & $\begin{array}{r}\text { Comunidades } \\
\text { quilombolas }\end{array}$ \\
\hline & & & & & & & 2011 \\
\hline \multirow{4}{*}{ NORTE } & $\begin{array}{l}\text { Índice de } \\
\text { envelhecimento }\end{array}$ & $8,2 \%$ & $8,9 \%$ & $10,7 \%$ & $14,6 \%$ & $24,6 \%$ & $18,1 \%$ \\
\hline & $\begin{array}{l}\text { Razão de dependência } \\
\text { total }\end{array}$ & $102,2 \%$ & $100,8 \%$ & $89,5 \%$ & $74,8 \%$ & $62,8 \%$ & $86,4 \%$ \\
\hline & $\begin{array}{l}\text { Razão de dependência } \\
\text { jovem }\end{array}$ & $94,5 \%$ & $92,6 \%$ & $80,9 \%$ & $65,3 \%$ & $50,4 \%$ & $73,2 \%$ \\
\hline & $\begin{array}{l}\text { Razão de dependência } \\
\text { idoso }\end{array}$ & $7,7 \%$ & $8,2 \%$ & $8,7 \%$ & $9,5 \%$ & $12,4 \%$ & $13,2 \%$ \\
\hline \multirow{4}{*}{ NORDESTE } & $\begin{array}{l}\text { Índice de } \\
\text { envelhecimento }\end{array}$ & $11,5 \%$ & $14,7 \%$ & $18,4 \%$ & $25,4 \%$ & $38,6 \%$ & $20,7 \%$ \\
\hline & $\begin{array}{l}\text { Razão de dependência } \\
\text { total }\end{array}$ & $99,5 \%$ & $98,8 \%$ & $87,4 \%$ & $70,6 \%$ & $58,4 \%$ & $83,6 \%$ \\
\hline & $\begin{array}{l}\text { Razão de dependência } \\
\text { jovem }\end{array}$ & $89,2 \%$ & $86,2 \%$ & $73,9 \%$ & $56,3 \%$ & $42,1 \%$ & $69,2 \%$ \\
\hline & $\begin{array}{l}\text { Razão de dependência } \\
\text { idoso }\end{array}$ & $10,3 \%$ & $12,6 \%$ & $13,6 \%$ & $14,3 \%$ & $16,3 \%$ & $14,3 \%$ \\
\hline \multirow{4}{*}{ SUDESTE } & $\begin{array}{l}\text { Índice de } \\
\text { envelhecimento }\end{array}$ & $14,8 \%$ & $18,8 \%$ & $25,3 \%$ & $34,9 \%$ & $54,6 \%$ & $25,3 \%$ \\
\hline & $\begin{array}{l}\text { Razão de dependência } \\
\text { total }\end{array}$ & $78,9 \%$ & $68,4 \%$ & $64,4 \%$ & $56,2 \%$ & $50,6 \%$ & $83,4 \%$ \\
\hline & $\begin{array}{l}\text { Razão de dependência } \\
\text { jovem }\end{array}$ & $68,7 \%$ & $57,6 \%$ & $51,4 \%$ & $41,7 \%$ & $32,7 \%$ & $66,6 \%$ \\
\hline & $\begin{array}{l}\text { Razão de dependência } \\
\text { idoso }\end{array}$ & $10,2 \%$ & $10,8 \%$ & $13,0 \%$ & $14,5 \%$ & $17,8 \%$ & $16,9 \%$ \\
\hline \multirow{4}{*}{ SUL } & $\begin{array}{l}\text { Índice de } \\
\text { envelhecimento }\end{array}$ & $11,1 \%$ & $16,6 \%$ & $24,0 \%$ & $33,5 \%$ & $55,0 \%$ & $15,4 \%$ \\
\hline & $\begin{array}{l}\text { Razão de dependência } \\
\text { total }\end{array}$ & $89,8 \%$ & $72,9 \%$ & $65,6 \%$ & $58,0 \%$ & $51,2 \%$ & $78,9 \%$ \\
\hline & $\begin{array}{l}\text { Razão de dependência } \\
\text { jovem }\end{array}$ & $80,8 \%$ & $62,5 \%$ & $52,9 \%$ & $43,4 \%$ & $33,0 \%$ & $68,4 \%$ \\
\hline & $\begin{array}{l}\text { Razão de dependência } \\
\text { idoso }\end{array}$ & $9,0 \%$ & $10,4 \%$ & $12,7 \%$ & $14,5 \%$ & $18,2 \%$ & $10,5 \%$ \\
\hline
\end{tabular}




\begin{tabular}{llcccccc}
\hline & $\begin{array}{l}\text { Índice de } \\
\text { envelhecimento }\end{array}$ & $7,7 \%$ & $10,2 \%$ & $14,4 \%$ & $22,1 \%$ & $36,0 \%$ & $28,4 \%$ \\
& $\begin{array}{l}\text { Razão de dependência } \\
\text { total }\end{array}$ & $93,1 \%$ & $82,6 \%$ & $67,8 \%$ & $57,6 \%$ & $49,9 \%$ & $95,8 \%$ \\
$\begin{array}{l}\text { CENTRO- } \\
\text {-OESTE }\end{array}$ & $\begin{array}{l}\text { Razão de dependência } \\
\text { jovem }\end{array}$ & $86,4 \%$ & $75,0 \%$ & $59,2 \%$ & $47,1 \%$ & $36,7 \%$ & $74,6 \%$ \\
& $\begin{array}{l}\text { Razão de dependência } \\
\text { idoso }\end{array}$ & $6,7 \%$ & $7,6 \%$ & $8,5 \%$ & $10,4 \%$ & $13,2 \%$ & $21,2 \%$ \\
\hline
\end{tabular}

Fonte: Cálculos a partir de IBGE - Censos demográficos nacionais de 1970 a 2010 e Banco de dados do DATAUFF.

Mais uma vez o Sul e o Sudeste parecem estar em outro momento da transição demográfica quando comparados às demais regiões. O índice de envelhecimento, por exemplo, é nestas duas primeiras, mais que o dobro do encontrado na região Norte e quase 20 pontos percentuais acima do que vemos nas demais. Por consequência, no eixo Sul-Sudeste a Razão de Dependência Idoso é mais elevada. Quando nos voltamos para a Razão de Dependência Jovem, o resultado da presença de uma população mais envelhecida no Sul-Sudeste aponta para taxas muito mais favoráveis (na casa dos 33,0\%) neste indicador, enquanto que a região Norte tem índice na casa dos 50,0\% e a região Nordeste na casa dos $42,0 \%$.

Entre a população quilombola investigada, o índice de envelhecimento é maior nas comunidades do Centro-Oeste e do Sudeste, mas sempre muito menor que aquele presente na população em geral. A Razão de Dependência Idoso, curiosamente, fica em índices próximos ao país nas regiões Norte, Nordeste e Sudeste.

A resultante do baixo envelhecimento populacional e do ainda elevado percentual de crianças e adolescentes é uma Razão de Dependência Total muito elevada entre os quilombolas, mas com variações entre as comunidades das cinco regiões. Assim, comparando cada conjunto de comunidades com a população regional total, podemos dizer que os quilombolas das regiões Sudeste e Centro-Oeste apresentavam Razão de Dependência Total semelhante à de suas respectivas regiões em 1970. Já os quilombolas do Sul, neste indicador, se aproximavam da população local em 1980. Enquanto que nas comunidades da região Norte e Nordeste a relação mais forte é com a configuração demográfica de 1991.

\section{Conclusões}

Não há uma correspondência forte entre os dados demográficos das 169 comunidades quilombolas pesquisadas e o perfil da transição demográfica nacional. A Razão de Dependência Total elevada $(86,4 \%)$, encontrada entre os quilombolas, remete à fase inicial do processo de transição demográfica brasileira - quando o peso da Razão de Dependência Jovem e a proporção de jovens com idade inferior a 15 anos também eram elevados. No caso das comunidades quilombolas, a Razão de Dependência Jovem (71,9\%) é muito alta, corroborando 
as características da população brasileira. Porém, a proporção de jovens com idade inferior a 15 anos $(38,6 \%)$ e de pessoas que têm 60 anos ou mais (7,7\%), encontrada nesse grupo, reflete um dado momento da transição, marcado por uma mudança significativa em direção ao envelhecimento da população. Já a média de 2,1 filhos por família entre este grupo específico, reproduz características observáveis no final do processo de transição brasileiro.

Os resultados para os quilombolas, somente em termos bem gerais e numa perspectiva tendencial, se aproximam daqueles encontrados para o Brasil; caracterizando a região Norte como de envelhecimento mais tardio e a região Sudeste com uma população mais envelhecida e numa fase do processo de transição mais adiantado. Embora, em ambos os casos, as idades ainda reflitam o perfil de uma população jovem.

As Razões de Dependência Total dos Quilombolas têm resultados bastante elevados em todas as regiões, superando os 78,0\% e não refletem os mesmos índices vigentes nas regiões brasileiras em 2010. Essas taxas são inerentes a populações em fases iniciais do processo de envelhecimento e que se assemelham às observadas nas décadas de 1970 e 1980 da transição demográfica brasileira.

Nesta direção, o processo de transição demográfica analisado à luz das comunidades quilombolas, reflete um perfil populacional de desenvolvimento tardio. Este possui características observadas no processo de transição brasileiro nas décadas de 1970, 1980 e 1990. A idade mediana de 20 anos verificada nesse grupo, remonta ao início da mudança no perfil de transição da população brasileira. Nessa fase, haveria uma redução nos índices de fecundidade e elevação na esperança de vida ao nascer.

A chamada "janela de oportunidades" ou "bônus demográfico" (ALVES, 2008; CARVALHO e BRITO, 2005), que corresponde ao momento da transição demográfica que o país vivencia atualmente, possibilitaria - em tese - o aproveitamento de uma elevada proporção de população em idade ativa para o desenvolvimento de ações produtivas economicamente estruturantes. Esta etapa do processo de transição tem início quando a proporção da população em idade ativa (de 15 a 59 anos) é igual ou maior que a Razão de Dependência Total. Considerando os dados apresentados aqui, vemos que a "janela de oportunidades" começa a ocorrer na década de 2000 para o Brasil como um todo e para as regiões Sudeste, Sul e Centro-Oeste, e em 2010 para as regiões Nordeste (somente o Norte ainda está ligeiramente aquém deste patamar, com 61,0\% de população entre 15 e 59 anos de idade e 62,8\% de Razão de Dependência Total).

Para as 169 comunidades quilombolas pesquisadas, esta janela ainda não se abriu, pois nestas, as pessoas em idade ativa correspondem a 53,7\% da população, enquanto que a Razão de Dependência Total está na casa dos 86,0\%. Quando desagregamos este dado por região, vemos que em nenhuma delas os quilombolas estariam sendo "bonificados".

A conclusão possível é que o processo de transição desse grupo populacional específico ainda está em andamento. Como vimos, o chamado "bônus demográfico" para este grupo ainda não ocorreu, o que pode ser verificado por suas elevadas Razão de Dependência Total 
e baixa proporção de pessoas em idade ativa. Estas comunidades, apresentavam elevados índices de envelhecimento em 2011, contudo todos os demais indicadores apontam para um perfil populacional jovem, onde a componente juvenil da Razão de Dependência ainda é muito superior à componente relativa aos idosos.

Para além da questão relativa à titulação definitiva de suas terras, que tem mobilizado o movimento quilombola e o Estado, o processo de transição demográfica pode ser utilizado para pensar políticas sociais de saúde, educação e acesso a programas de geração de renda que atendam eficientemente a essas comunidades. Além disso, se a chamada "janela de oportunidades" pela qual o Brasil atravessa, for aproveitada para pensar políticas de acesso; as comunidades quilombolas poderão lograr com seus efeitos, visto que seu bônus demográfico chegará mais tardiamente que para a média dos brasileiros.

\section{Referências}

ABA. Documento do grupo de trabalho sobre comunidades negras rurais. Rio de Janeiro: 17/18 de 1994. ALMEIDA, Alfredo Wagner Berno de. Nas bordas da política étnica: os quilombos e as políticas sociais. In: Boletim Informativo Nuer, v. 2, nº 2, Florianópolis: NUER/UFSC, 2005.

(Orgs.) et al. Cadernos de debates nova cartografia social: territórios quilombolas e conflitos. Manaus: Projeto Nova Cartografia Social da Amazônia, UEA edições, 2010.

ALVES, José E. D. Alves. A polêmica Malthus versus Condorcet reavaliada à luz da transição demográfica. Rio de Janeiro: Escola Nacional de Ciências Estatísticas; 2002. Disponível em: http://sociales.cchs.csic.es/jperez/ pags/Teorias/Textos/Diniz2002.pdf. Acesso em: 03/01/2017.

A transição demográfica e a janela de oportunidade. São Paulo: Instituto Fernand Braudel de Economia Mundial, 2008.

ANDRADE, Lucia. O Papel da Perícia Antropológica no Reconhecimento das Terras de Ocupação Tradicional O Caso das Comunidades Remanescentes de Quilombos do Trombetas (Pará). In: A Perícia Antropológica em Processos Judiciais. Florianópolis: Editora da UFSC, 1994.

ANJOS. José Carlos Gomes dos Anjos. Remanescentes de quilombos: reflexões epistemológicas. In: LEITE, Ilka Boaventura (Org). Laudos periciais antropológicos em debate. Florianópolis: Co-edição NUER/ABA, 2005.

BARTH, Fredrik. "Os grupos étnicos e suas fronteiras". In: O guru, o iniciador e outras variações antropológicas. Rio de Janeiro: Contra Capa Livraria, 2000.

BRANDÃO, André.; DA DALT, Salete.; GOUVEIA, Vitor. Comunidades quilombolas no Brasil: características socioeconômicas, processos de etnogênese e políticas sociais. Niterói: EDUFF, 2010.

.; JORGE, Amanda. Lacerda. Avaliação da situação socioeconômica das comunidades quilombolas já tituladas: crônica de um mau resultado anunciado. Trabalho apresentado no XVII Congresso Brasileiro de Sociologia, Porto Alegre, Julho de 2015.

CARVALHO, José. A. Magno de; BRITO, Fausto. A demografia brasileira e o declínio da fecundidade no Brasil: contribuições, equívocos e silêncios. Revista Brasileira de Estudos de População. Volume 22 (número 2), p. 351-369, 2005. 
DATAUFF. Relatório Final da Avaliação da Situação de Segurança Alimentar e Nutricional em Comunidades Quilombolas Tituladas. Niterói, Datauff, 2012.

JORGE, Amanda. Lacerda. Os caminhos de acesso ao regime de segurados especiais da previdência rural e ao benefício de prestação continuada na comunidade Quilombola da Lapinha-MG. Dissertação de Mestrado em Desenvolvimento Social. PPGDS-UNIMONTES, 2012.

LANDRY, Adolphe. La révolution démographique: études e essais sur les problémes de la population. Paris: Librarie du Recueil Sirey; 1934.

O’DWYER, Eliane Cantarino. Terras de quilombo no Brasil: direitos territoriais em construção. In: ALMEIDA, Alfredo Wagner Berno de (orgs.) et al. Cadernos de debates nova cartografia social: territórios quilombolas e conflitos. Manaus: Projeto Nova Cartografia Social da Amazônia, UEA edições, 2010.

SEPPIR. Programa Brasil Quilombola. Brasília, 2004.

. Programa Brasil Quilombola: relatório de gestão. Brasília, 2012.

SOARES, Laura Tavares. R. América Latina: transição epidemiológica ou retrocesso social? Acta Paulista de Enfermagem. Volume 13 (número especial parte 1), 2000.

VASCONCELOS, Ana M. Nogales.; GOMES, Marília. M. Forte. Transição demográfica: a experiência brasileira. Epidemiologia e Serviços de Saúde. Volume 21, Número 4, 2012.

THOMPSON, Warren Simpson. Population. American Journal of Sociology. 34(6), p. 47-69, 1929.

Recebido em 05/01/2017

Aceito em 13/03/2018 